\title{
Cyclodextrins and ternary complexes: technology to improve solubility of poorly soluble drugs
}

\author{
Janisse Crestani de Miranda ${ }^{1}$, Tércio Elyan Azevedo Martins' ${ }^{1}$, Francisco Veiga ${ }^{2}$, \\ Humberto Gomes Ferraz ${ }^{1, *}$
}

\author{
${ }^{1}$ Department of Pharmacy, Faculty of Pharmaceutical Sciences, University of São Paulo, ${ }^{2}$ Faculty of Pharmacy, \\ University of Coimbra
}

\begin{abstract}
Cyclodextrins (CDs) are cyclic oligosaccharides composed of D-glucopyranoside units linked by glycosidic bonds. Their main property is the ability to modify the physicochemical and biological characteristics of low-soluble drugs through the formation of drug: $\mathrm{CD}$ inclusion complexes. Inclusion complexation requires that host molecules fit completely or partially within the CD cavity. This adjustment is directly related to the physicochemical properties of the guest and host molecules, easy accommodation of guest molecules within the CD cavity, stoichiometry, therapeutic dose, and toxicity. However, dosage forms may achieve a high volume, depending on the amount of $\mathrm{CD}$ required. Thus, it is necessary to increase solubilization efficiency in order to use smaller amounts of $\mathrm{CD}$. This can be achieved by adding small amounts of water-soluble polymers to the system. This review addresses aspects related to drug complexation with CDs using water-soluble polymers to optimize the amount of $\mathrm{CD}$ used in the formulation in order to increase drug solubility and reduce dosage form volume.
\end{abstract}

Uniterms: Cyclodextrins. Ternary complexes. Drugs/complexation. Water-soluble polymers/use. Drugs/ solubility. Inclusion complexe.

Ciclodextrinas (CDs) são oligossacarídeos cíclicos, compostos por unidades D-glicopiranosídicas ligadas entre si por meio de ligações glicosídicas e sua principal propriedade está na capacidade de alterar as características físico-químicas e biológicas de fármacos com baixa solubilidade por meio da formação de complexos de inclusão fármaco:CD. Para a formação dos complexos de inclusão a molécula hospedeira necessita ajustar-se total ou parcialmente no interior da cavidade da $\mathrm{CD}$, onde este ajuste está diretamente ligado a propriedades físico-químicas da molécula hóspede e hospedeira, facilidade de alojamento da molécula hóspede no interior da cavidade da $\mathrm{CD}$, estequiometria, dose terapêutica e toxicidade. No entanto, as formas farmacêuticas podem atingir um elevado volume, em função da quantidade de CD requerida, sendo necessário aumentar sua eficiência de solubilização para que seja possível utilizar menores quantidades das mesmas. Isso pode ser obtido com a inclusão de pequenas quantidades de polímeros hidrossolúveis ao sistema. Nessa revisão, são abordados aspectos relacionados à complexação de fármacos com ciclodextrinas empregando-se polímeros hidrossolúveis para otimização da quantidade de CD utilizada na formulação, com a finalidade de aumentar a solubilidade do fármaco e reduzir o volume das preparações.

Unitermos: SCiclodextrinas. Complexos ternários. Fármacos/complexação. Polímeros hidrossolúveis/ uso. Fármacos/solubilidade. Complexos de inclusão.

\section{INTRODUCTION}

Among several factors, solubility in water is of paramount importance in the development of a sufficiently

*Correspondence: H. G. Ferraz. Departamento de Farmácia, Faculdade de Ciências Farmacêuticas - USP. Av. Prof. Lineu Prestes, 580 - Cidade Universitária, 05508-900 - São Paulo - SP, Brasil. E-mail: sferraz@usp.br safe and effective dosage formulation, because preparation, absorption and even the biological activity of a drug are all dependent on its solubility. However, the amount of lipophilic molecules used in treatment is relatively high and tends to increase, considering that many different drugs have low solubility (Lipinski, 2000; Grant, Zhang, 2011). 
Thus, use of cyclodextrins (CDs) is one of several technologies available to improve the solubility of poorly water-soluble drugs. The most remarkable property of CDs is their ability to modify the physicochemical characteristics of molecules that are accommodated within their internal cavity to form the so-called inclusion complexes (Loftsson, Brewster, 1997; Tsai et al., 2010).

Typical characteristics of formulations containing inclusion complexes include a faster dissolution rate and shorter drug release time, as well as more efficient absorption. This translates into greater oral bioavailability of the drugs involved and an increase in biological activity, which may result in a reduction in drug dosage (Valle, 2004; Garnero et al., 2010).

However, the use of CDs is limited in some cases, because guest molecules need to fit completely or partially within the CD cavity. This adjustment is directly related to the physicochemical properties of the guest and host molecules, easy accommodation of guest molecules within the CD cavity, stoichiometry, therapeutic dose, and CD toxicity (Loftsson, Brewster, 1997).

An increase in formulation volume represents a critical stage in the applicability of CD inclusion complexes. We can consider that $1 \mathrm{~g}$ of a solid complex corresponds to $100-250 \mathrm{mg}$ of a drug (when the molecular weights of the drug and the CD are 200-400 g/mol and 1200-1500 g/mol, respectively). Therefore, the use of CDs in oral solid dosage forms is limited to drug doses less than $200 \mathrm{mg}$ that have good complexation properties (Loftsson, Brewster, 1996).

A strategy often used to improve complexation between drugs and CDs is the addition of small amounts of water-soluble polymers to the system, which causes an increase in solubilization efficiency, while requiring smaller amounts of CD (Loftsson, Fridriksdóttir, 1998; Mura et al., 2001). These results can be attributed to the synergistic effect of polymer and CD solubilization on the formation of drug:CD:water-soluble polymer ternary complexes (Carrier et al., 2007).

Water-soluble polymers are able to interact with drugs, $\mathrm{CD}$ molecules, and even with drug:CD complexes
(Loftsson et al., 1996). The mechanism involved in increasing CD complexation efficiency in the presence of water-soluble polymers is not yet fully understood; however, it is believed that water-soluble polymers can reduce CD mobility and increase the complex solubility (Veiga et al., 2006). The addition of water-soluble polymers has been shown to increase drug bioavailability and cause an up to $80 \%$ reduction in the amount of CD required (Loftsson, Fridriksdóttir, 1998; Mura et al., 2001).

The purpose of this study is to outline the relevance of using CDs to improve the solubility of poorly watersoluble drugs, with special emphasis on their structural characteristics, physicochemical properties, productive processes, toxicity, derivatives, and use in the pharmaceutical industry. Despite the recognized benefits of ternary (drug:CD:water-soluble polymer) complexes, there have been no reviews on the subject in the scientific literature. This review addresses aspects related to drug complexation with CDs using water-soluble polymers to increase drug solubility and reduce dosage form volume.

\section{CYCLODEXTRINS (CDs)}

CDs are cyclic oligosaccharides composed of Dglucopyranoside units (glucose) linked by $\alpha-1.4$ glycosidic bonds. They are obtained from biotechnological processes involving the enzymatic degradation of corn starch and offer greater yield with 6,7 and 8 units of glucose, known as $\alpha-C D, \beta-C D$ and $\gamma-C D$, respectively (Szejtli, 1998; Heise et al., 2010) (Figure 1).

CDs with less than 6 units of glucose do not exist for stoichiometric reasons and those with more than 8 units offer low yields and weak complexing properties, thus making them unsuitable for the pharmaceutical industry (Loftsson, Brewster, 1997; Jug et al., 2011).

According to Szejtli (2004), the history of CDs can be divided into three distinct periods (Figure 2), as follows: (a) discovery, from 1891 to 1930; (b) development, from 1930 to 1970, and (c) industrial use, from 1970 onwards. In the beginning of the industrial production of CDs
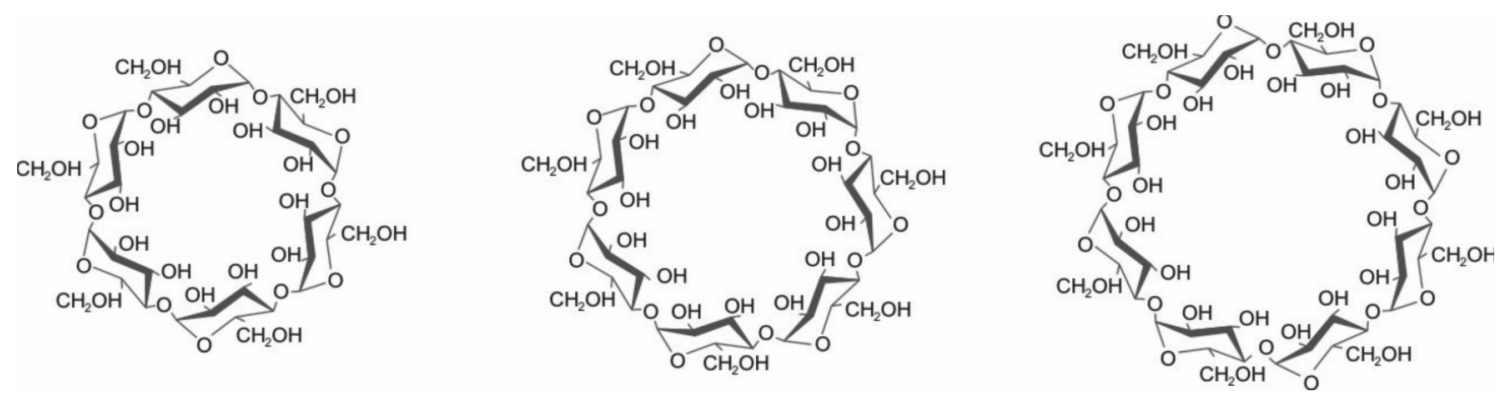

FIGURE 1 - Chemical structure of $\alpha$-, $\beta$ - and $\gamma$-cyclodextrins, respectively. Adapted from Veiga et al., 2006. 


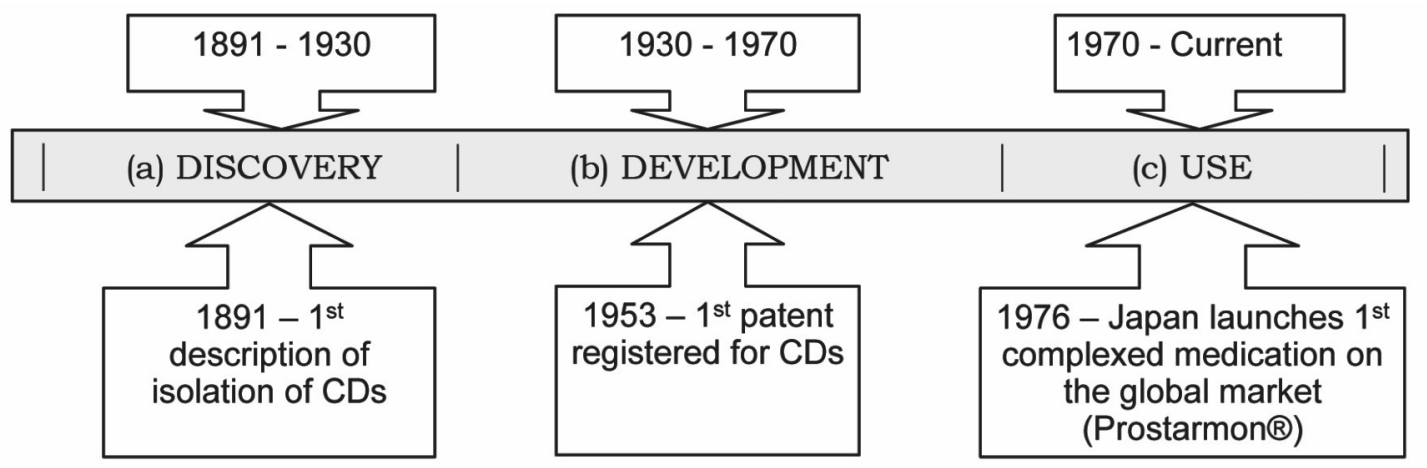

FIGURE 2 - Timeline of relevant events in the history of cyclodextrins (CDs).

(treating the starch with Bacillus macerans), the final product was a mixture of $\alpha-\mathrm{CD}(60 \%), \beta-\mathrm{CD}(20 \%)$ and $\gamma-\mathrm{CD}(20 \%)$, as well as small amounts of CDs with more than 8 units of glucose. However, purity was a major hurdle, becoming a critical issue that had to be overcome before the use of CDs could be made possible (Loftsson, Duchêne, 2007).

An alternative to address the issue of impurity was the use of biotechnological processes, which, along with other innovations, led to an increased purity of the resulting $\mathrm{CD}$, thus making their use as pharmaceutical excipients feasible (Loftsson et al., 2005b).

\section{Cyclodextrin structure}

Due to the lack of free rotation about the glycosidic bonds and chain conformation of glucose units, CDs display a torus-like or hollow truncated cone shape. In this peculiar structure (Figure 3), the secondary hydroxyl

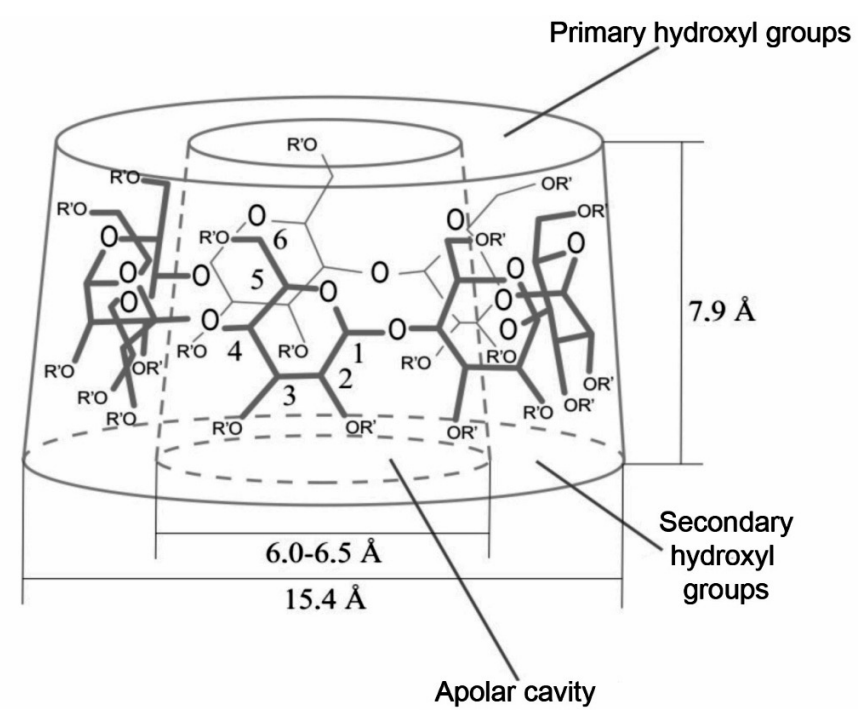

FIGURE 3 - $\beta$-cyclodextrin ( $\beta$-CD) structure, with representations of its size and position of hydroxyl groups. groups can be found at the broadest end, bonded to the $\mathrm{C} 2$ and $\mathrm{C} 3$ atoms of the glucose units, while the primary hydroxyl groups are located at the narrower opposite end, bonded to the C6 atoms of the glucose units (Bekers et al., 1991; Loftsson et al., 2004; Veiga et al., 2006).

The molecular arrangement of CDs is a result of the free rotation of primary hydroxyl groups, which reduces the diameter of the cavity at its narrowest end, i.e., the end with the smallest molecular diameter. $\mathrm{CH}$ groups bonded to the $\mathrm{H} 1, \mathrm{H} 2$ and $\mathrm{H} 4$ hydrogen atoms can be found on the outside of the molecule, while the hydroxyls find their way outside the truncated cone, thus becoming the external layer of hydrophilic CDs (Brewster, Loftsson, 2007).

In the internal layer, $\mathrm{CH}$ groups are bonded to the $\mathrm{H} 3$ and $\mathrm{H} 5$ hydrogen atoms by glycosidic oxygen bridges. Intramolecular hydrogen bonds between the $\mathrm{C} 2-\mathrm{OH}$ groups of a glucose unit and the C3-OH groups of an adjacent glucose unit stabilize the CD structure, making it rigid (Loftsson, Brewster, 1997; Brewster, Loftsson, 2007).

\section{Properties}

The most important property of CDs is their ability to modify the physicochemical and biological characteristics of drugs. Their cavity can establish interactions through intermolecular forces with molecules, ions or radicals, acting as a host substance. The resulting molecular complex is called an inclusion compound or a supramolecular compound (Loftsson, Brewster, 1997; Li et al., 2010).

Table I details several characteristics of natural CDs. Table II lists the solubility of natural CDs in water and other organic solvents.

Of all natural CDs, $\beta$-CD has the lowest solubility, due to the high number of intramolecular hydrogen bonds among secondary hydroxyl groups within the molecule. These interactions make the structure rigid and prevent hydration by water molecules (Szejtli, 1994; Loftsson et al., 2005b). 
TABLE I - Properties of natural cyclodextrins (CDs) (Adapted from: Szejtli, 1994; Veiga et al., 2006; Brewster, Loftsson, 2007; Wintgens and Amiel, 2010)

\begin{tabular}{lccc}
\hline Property & $\alpha$-CD & $\beta$-CD & $\gamma$-CD \\
\hline Glucose units & 6 & 7 & 8 \\
Molecular weight $(\mathrm{g} / \mathrm{mol})$ & 972 & 1135 & 1297 \\
External diameter $(\AA)$ & 14.6 & 15.4 & 17.5 \\
Internal diameter $(\AA)$ & $4.7-5.3$ & $6.0-6.5$ & $7.5-8.3$ \\
Height $(\AA)$ & 7.9 & 7.9 & 7.9 \\
Cavity volume $(\AA)$ & 174 & 262 & 427 \\
Shape of crystals & Hexagonal lattice & Monocyclic parallelograms & Quadratic prism \\
pKa by potentiometry $\left(25^{\circ} \mathrm{C}\right)$ & 12.333 & 12.202 & 12.081 \\
Diffusion constant at $40^{\circ} \mathrm{C}(\mathrm{m} / \mathrm{s})$ & 3.443 & 3.232 & 3.000 \\
Hydrolysis by $\alpha$-amylase & Negligible & Slow & Fast \\
\hline
\end{tabular}

TABLE II - Solubility (g/100 mL) of natural cyclodextrins (CDs) (Adapted from: Szejtli, 1994; Loftsson et al., 2005b)

\begin{tabular}{lccc}
\hline Solvent & $\alpha-\mathrm{CD}$ & $\beta-\mathrm{CD}$ & $\gamma$-CD \\
\hline Water $\left(25^{\circ} \mathrm{C}\right)$ & 14.5 & 1.85 & 23.2 \\
Ethyl ether & Insoluble & Insoluble & Insoluble \\
Chloroform & Insoluble & Insoluble & Insoluble \\
Isopropanol & Insoluble & Insoluble & $>0.1$ \\
Acetone & Insoluble & Insoluble & $>0.1$ \\
Ethanol & Insoluble & Insoluble & $>0.1$ \\
Methanol & Insoluble & Insoluble & $>0.1$ \\
Glycerin & Insoluble & 4.3 & - \\
Propylene glycol & 1 & 2 & - \\
Dimethyl sulfoxide & 2 & 35 & - \\
Pyridine & 7 & 37 & - \\
Ethylene glycol & 9 & 21 & - \\
Dimethylformamide & 54 & 32 & - \\
\hline
\end{tabular}

In $\alpha-C D$, only 4 of 6 possible hydrogen bonds can be established, because one of the glucose units is in a distorted position. The $\gamma$-CD is a noncoplanar, more flexible structure, thus being the most soluble of the three CDs (Loftsson et al., 2005b).

CDs are stable in alkaline medium, hydrolyze in strongly acidic medium and are resistant to enzymatic degradation by $\beta$-amylase, although CDs, particularly $\gamma-\mathrm{CD}$, are susceptible to attack by $\alpha$-amylase. CDs can form stable hydrates and their stability is identical to that of starch; thus, they can be stored for years without suffering any degradation (Szejtli, 1994).

\section{Toxicity}

The safety profile of natural CDs and their derivatives has been widely studied, and they have generally proven to be atoxic, because they only manage to cross biological membranes with some degree of difficulty. Thus, oral administration of CDs should not be regarded as a problem (Valle, 2004).

Conversely, parenteral administration of $\gamma-C D$, 2-hydroxypropyl- $\beta$-CD (2-HP- $\beta$-CD), sulfobutylether- $\beta$ $\mathrm{CD}(\mathrm{SBE}-\beta-\mathrm{CD})$, sulfate- $\beta-\mathrm{CD}$ and maltose- $\beta-\mathrm{CD}$ is safe to some degree. Studies have proven that several alkylating derivatives of $\alpha$ - and $\beta$-CDs are not recommended for use via this route of administration, because they show nephrotoxicity and hemolytic activity (Loftsson, Duchêne, 2007).

\section{CYCLODEXTRINS AND THEIR DERIVATIVES}

It is possible to introduce chemical modifications into the primary and secondary hydroxyl groups of natural CDs through the bonds of several functional groups, thus 
improving solubility, toxicity and increasing the inclusion capacity of original CDs and their derivatives (Uekama, Irie, 2004).

CD derivatives can be obtained by substitution with methyl, ethyl, carboxymethyl, hydroxyethyl, hydroxypropyl, sulfobutyl, or saccharide groups or even by polymerization of CDs. Many derivatives of natural CDs have been synthesized and characterized, but only a few are being used in studies involving new pharmaceutical excipients, including derivatives with methyl, hydroxypropyl and sulfobutyl ether substitutes (Mosher, Thompson, 2002; Uekama, Irie, 2004; Veiga et al., 2006).

\section{HYDROPHILIC DERIVATIVES}

\section{Methylated derivatives}

These derivatives can be obtained by selective methylation of all secondary hydroxyl groups in $\mathrm{C} 2$ and all primary hydroxyls in C6, methylation of all hydroxyl groups, including those in $\mathrm{C} 3$, or even randomly, in the $\mathrm{C} 2$, C3 or C6 positions (Imai et al., 1984; Veiga et al., 2006).

The methylated derivatives show alterations in their physical and chemical properties, as well as structural alterations when compared to natural CDs (Table III). Solubility in water and organic solvents is significantly greater; however, water solubility decreases as the temperature increases (a reaction similar to that of nonionic surfactants). These derivatives exhibit reasonable stability in alkaline medium and are hydrolyzed by strong acids, giving rise to linear oligosaccharides (Uekama, Irie, 2004; Veiga et al., 2006).

Dimethyl- $\beta-C D$ is the least vulnerable to acid hydrolysis. At the opposite extreme, trimethyl- $\gamma-\mathrm{CD}$ is the most susceptible, due to severe distortion in the configuration of the CD ring (Uekama, Irie, 2004).

\section{Hydroxyalkyl derivatives}

Hydroxyalkyl derivatives are one of the derivative groups most commonly used in drug complexation, being represented primarily by 2 -hydroxyethyl- $\beta$-CD $(2-\mathrm{HE}-\beta-$ CD), 2-HP- $\beta$-CD, 3-hydroxypropyl- $\beta$-CD (3-HP- $\beta-C D)$, and 2.3-dihydroxypropyl- $\beta$-CD (2.3-DHP- $\beta-C D)$. Obtaining hydroxylated CDs from $\alpha-C D$ and $\gamma$-CD shows no significant benefits compared to $\beta$-CD derivatives (Uekama, Otagari, 1998).

Obtaining hydroxyalkyl derivatives is a non-selective process that occurs by the condensation of hydroxyalkylating agents (hydroxypropyl and hydroxyethyl) in alkaline medium. The product of the condensation reaction is invariably a mixture of the respective derivatives, with various degrees of substitution. These mixtures not only prevent recrystallization, but also result in the conversion of the drug from a crystalline state into an amorphous state (Uekama, Otagari, 1998; Uekama et al., 2006).

The degree of substitution (S) expresses the number of hydroxyl groups replaced in a unit of glucose, which may range from 1 to 3 , and the average degree of substitution (DS) expresses the average number of hydroxyls replaced per unit of glucose, which is between 0 and 3. The average molar substitution (MS) expresses the number of hydroxypropyl groups per unit of glucose (Veiga et al., 2006).

Hydroxyalkyl derivatives have high water solubility and low hygroscopicity compared to the original CD; thus, in the presence of high humidity $(>90 \%)$, they dissolve in water adsorption. They have a surface tension identical

TABLE III - Physicochemical properties of cyclodextrins (CDs) and their methylated derivatives. Source: Duchêne and Wouessidjewe, 1990a and $1990 \mathrm{~b}$

\begin{tabular}{lccccccc}
\hline CD & $\begin{array}{c}\text { Glucose } \\
\text { unit }\end{array}$ & $\begin{array}{c}\text { Molecular } \\
\text { weight }\end{array}$ & $\begin{array}{c}\text { Internal cavity } \\
\text { diameter }(\AA)\end{array}$ & $\begin{array}{c}\text { Melting point } \\
\left({ }^{\circ} \mathrm{C}\right)\end{array}$ & $\begin{array}{c}\text { Aqueous } \\
\text { solubility } 25{ }^{\circ} \mathrm{C} \\
(\mathrm{g} / 100 \mathrm{~mL})\end{array}$ & $\begin{array}{c}\text { Water } \\
\text { content }\end{array}$ & $\begin{array}{c}\text { Surface tension } \\
(\mathrm{mN} / \mathrm{m})\end{array}$ \\
\hline$\alpha-\mathrm{CD}$ & 6 & 973 & 5 & 275 & 15 & 10 & 71 \\
Dimethyl- $\alpha-\mathrm{CD}$ & 6 & 1141 & 5 & $260-264$ & ---- & --- & 65 \\
Trimethyl- $\alpha-\mathrm{CD}$ & 6 & 1225 & $3-6$ & 205 & 20 & 10 & 54 \\
$\beta-\mathrm{CD}$ & 7 & 1153 & 6 & 280 & 1.85 & 10 & 71 \\
Dimethyl- $\beta-\mathrm{CD}$ & 7 & 1331 & 6 & $295-300$ & 57 & 1 & 62 \\
Trimethyl- $\beta-\mathrm{CD}$ & 7 & 1430 & $4-7$ & 157 & 31 & 10 & 56 \\
$\gamma$-CD & 8 & 1297 & 8 & 275 & 23 & 10 & 71 \\
Dimethyl- $\gamma-\mathrm{CD}$ & 8 & 1521 & 8 & $255-260$ & --- & --- & 60 \\
Trimethyl- $\gamma-\mathrm{CD}$ & 8 & 1634 & $5-9$ & 135 & 48 & ---- & 56 \\
\hline
\end{tabular}


to that of natural CDs, but this characteristic is altered in derivatives with high degrees of substitution (Uekama, Otagari, 1998; Uekama et al., 2006).

\section{Ramified derivatives}

This class of CDs is obtained by chemical or enzymatic synthesis, where the substitution of primary or secondary hydroxyl groups for mono- or disaccharides through $\alpha-(1.6)$ bonds results in the formation of ramified CDs with high water solubility and chemical purity (Veiga et al., 2006).

Although ramified CDs have physical and chemical properties similar to those of natural CDs, such as surface tension and complexation capacity (Table IV), their solubility in water, as well as in aqueous solutions of ethanol, methanol, acetone, formaldehyde and ethylene glycol, is superior (Duchêne Wouessidjewe, 1990b).

\section{HYDROPHOBIC DERIVATIVES}

CDs and their derivatives are mainly used in the pharmaceutical industry to improve the solubility and dissolution speed of poorly soluble drugs by means of inclusion complexation. However, some CD derivatives act in an opposite manner, with the main function of controlling the dissolution speed of water-soluble drugs. These derivatives are represented by ethylated and acylated CDs (Uekama et al., 2006).

\section{Ethylated derivatives}

The aqueous solubility of CDs is reduced when their hydroxyl groups are replaced with alkyl groups larger than methyl, through an ether or ester bond. Solubility decreases proportionally to the rate of substitution, which increases in less polar solvents, thus presenting fewer hygroscopic characteristics and lower surface tension (Uekama et al., 2006; Mosher, Thompson, 2002).

\section{Acylated derivatives}

These are obtained by substitution of all $\beta$-CD hydroxyl groups for different alkyl chains, resulting in reduced aqueous solubility, melting point and rate of alkaline hydrolysis as the respective alkyl chain increases. In concentrated solutions of $\beta-C D$ derivatives in organic solvents (ethanol, acetone or chloroform), the viscosity increases due to a gelation process occurring after the solvent has evaporated (Mosher, Thompson, 2002).

Differently from the ethylated $\beta-C D$ derivatives, acylates are easily eliminated from the organism after alkaline hydrolysis, yielding the original $C D(\beta-C D)$. This is an important factor in the event of enteral administration, because this CD is not toxic when administered by this route (Mosher, Thompson, 2002).

\section{Ionizable derivatives}

The substitution of CD hydroxyl groups for ionizable groups imparts hydrophilic characteristics to the new structure, as well as $\mathrm{pH}$-dependent complexation capacity. In other words, solubility is low in acidic medium, becoming greater in neutral or alkaline media. This $\mathrm{pH}$-dependent characteristic is a result of the ionization of the carboxylic groups that show a pKa value around 3.5 (Ma et al., 2000).

Among all ionizable CDs, one in particular stands out: SBE- $\beta-C D$. This is a polyanionic $\mathrm{CD}$ formed when the 2, 3 and 6 hydroxyl groups of $\beta-C D$ glucose units are substituted for sulfobutyl ether groups, which are totally ionized over a broad $\mathrm{pH}$ range. They provide a negatively

TABLE IV - Physicochemical properties of cyclodextrins (CDs) and their ramified derivatives (Duchêne, Wouessidjewe, 1990a and 1990b)

\begin{tabular}{lcccc}
\hline Molecule & Glucose units & Molecular weight & $\begin{array}{c}\text { Aqueous solubility } 25^{\circ} \mathrm{C} \\
(\mathrm{g} / 100 \mathrm{~mL})\end{array}$ & $\begin{array}{c}\text { Surface tension } \\
(\mathrm{mN} / \mathrm{m})\end{array}$ \\
\hline$\alpha$-CD & 6 & 973 & 18.0 & 71 \\
Glycosyl- $\alpha-\mathrm{CD}$ & 7 & 1135 & 89.0 & --- \\
$\beta-\mathrm{CD}$ & 6 & 1135 & 18.5 & 71 \\
Glycosyl- $\beta-\mathrm{CD}$ & 8 & 1297 & 97.0 & 71 \\
Diglycosyl- $\beta-\mathrm{CD}$ & 9 & 1459 & 140 & --- \\
Maltosyl- $\beta-\mathrm{CD}$ & 9 & 1459 & 50 & 70 \\
Dimaltosyl- $\beta-\mathrm{CD}$ & 11 & 1789 & 50 & 71 \\
$\gamma$-CD & 8 & 1297 & 23 & 71 \\
\hline
\end{tabular}


charged polar head, attached to a hydrophobic tail, which is connected to the internal cavity (Stella et al., 2002).

SBE- $\beta$-CD has a peculiar structure, where substitute groups that exercise mutual electrostatic repulsion are in a favorable position for entry into the CD cavity. As a result, there is an increase in its hydrophobic proper- ties and complexation capacity, which is the reason for its wide-ranging pharmaceutical application. Another relevant attribute is the fact that the charge of the $\mathrm{CD}$ molecule is located at a site as far as possible from the hydrophobic cavity, thus intensifying its solubilizing capacity (Zia et al., 2001).

TABLE V - Details of some characteristics of cyclodextrin (CD) derivatives

\begin{tabular}{|c|c|c|c|c|}
\hline Derivative & Method & Characteristics & Advantages & Disadvantages \\
\hline \multicolumn{5}{|c|}{ Hydrophilic derivatives } \\
\hline Methylates & Methylation & $\begin{array}{c}\text { Water solubility } \\
\text { decreases as temperature } \\
\text { increases }\end{array}$ & $\begin{array}{c}\text { Solubility in water } \\
\text { greater than natural } \mathrm{CD} \text {; } \\
\text { very soluble in organic } \\
\text { solvents }\end{array}$ & $\begin{array}{l}\text { Hydrolyzed in the } \\
\text { presence of strong acids }\end{array}$ \\
\hline Hydroxyalkyl & $\begin{array}{c}\text { Condensation of } \\
\text { hydroxyalkylating } \\
\text { agents in alkaline } \\
\text { medium }\end{array}$ & $\begin{array}{l}\text { Surface tension identical } \\
\text { to that of natural CD. } \\
\text { Lower surface tension } \\
\text { observed only in } \\
\text { derivatives with high rate } \\
\text { of substitution }\end{array}$ & $\begin{array}{l}\text { Highly soluble in water; } \\
\text { low hygroscopicity }\end{array}$ & $\begin{array}{l}\text { In the presence of } \\
\text { humidity }>90 \% \text {, they } \\
\text { dissolve in water } \\
\text { adsorption }\end{array}$ \\
\hline$\overline{\text { Ramified }}$ & $\begin{array}{c}\text { Chemical or enzymatic } \\
\text { synthesis }\end{array}$ & $\begin{array}{c}\text { Substitution of } \\
\text { primary and secondary } \\
\text { hydroxyls for mono- and } \\
\text { disaccharides through } \\
\alpha-(1.6) \text { bonds. } \\
\text { They present three } \\
\text { types of hydrolyzable } \\
\text { glycosidic bonds: } \alpha-(1.6) \\
\text { between the CD ring and } \\
\text { the ramification unit, } \\
\alpha-(1.4) \text { of the glucose } \\
\text { units of lateral chain, } \\
\text { and } \alpha-(1.4) \text { bonds of the } \\
\text { chain ring } \\
\end{array}$ & $\begin{array}{l}\text { High solubility in water } \\
\text { and aqueous solutions } \\
\text { of methanol, ethanol, } \\
\text { acetone, formaldehyde } \\
\text { and ethylene glycol }\end{array}$ & $\begin{array}{l}\text { Chemical degradation } \\
\text { increases as } \mathrm{pH} \\
\text { decreases }\end{array}$ \\
\hline \multicolumn{5}{|c|}{ Hydrophobic derivatives } \\
\hline Ethylates & $\begin{array}{l}\text { Partial ethylation of } \\
\text { hydroxyl groups }\end{array}$ & $\begin{array}{l}\text { Solubility decreases } \\
\text { proportionally to the } \\
\text { rate of substitution and } \\
\text { increases in less polar } \\
\text { solvents }\end{array}$ & $\begin{array}{l}\text { Prolonged drug release } \\
\text { time }\end{array}$ & $\begin{array}{l}\text { Reduction in aqueous } \\
\text { solubility of CDs }\end{array}$ \\
\hline Acylates & $\begin{array}{l}\text { Substitution of } \\
\text { hydroxyl groups for } \\
\text { different alkyl chains }\end{array}$ & $\begin{array}{c}\text { Aqueous solubility, } \\
\text { melting point and rate } \\
\text { of alkaline hydrolysis } \\
\text { decreases as alkyl chain } \\
\text { increases }\end{array}$ & $\begin{array}{l}\text { Easily eliminated from } \\
\text { the organism after } \\
\text { alkaline hydrolysis }\end{array}$ & $\begin{array}{c}\text { High viscosity in } \\
\text { solvents such as } \\
\text { ethanol, acetone, and } \\
\text { chloroform. Gelation } \\
\text { occurs after the solvent } \\
\text { evaporates }\end{array}$ \\
\hline Ionizable & $\begin{array}{l}\text { Substitution of } \\
\text { hydroxyl groups for } \\
\text { ionizable groups }\end{array}$ & $\begin{array}{l}\text { Hydrophily and capacity } \\
\text { for } \mathrm{pH} \text {-dependent } \\
\text { complexation }\end{array}$ & $\begin{array}{c}\text { High solubility in } \\
\text { neutral or alkaline } \mathrm{pH}\end{array}$ & $\begin{array}{l}\text { Low solubility in acidic } \\
\mathrm{pH}\end{array}$ \\
\hline
\end{tabular}




\section{FORMATION OF INCLUSION COMPLEXES}

The truncated cone structure of CDs, which are open at both ends, enables the inclusion of a wide variety of organic molecules (apolar drugs) in their central cavities. Host-guest complexes, or drug-CD complexes also known as inclusion complexes or compounds, result from the association between host molecules (CDs) and encapsulated molecules (drugs) (Szejtli, 1998; Tsai et al., 2010).

The formation of a complex (Figure 4) in an aqueous solution takes place when water molecules are removed from the apolar cavity of CDs (which are in an energetically unfavorable environment due to the nature of the polar-polar interaction) and substituted for a guest molecule or lipophilic group with polarity, size and shape compatible with that of the CD structure (Szejtli, 1998; Rafati et al., 2009).

This process is energetically favorable and contributes to an increase in complex stability, because it causes changes in enthalpy and a reduction in the total energy of the system (Saenger, 1980; Veiga et al., 2006).

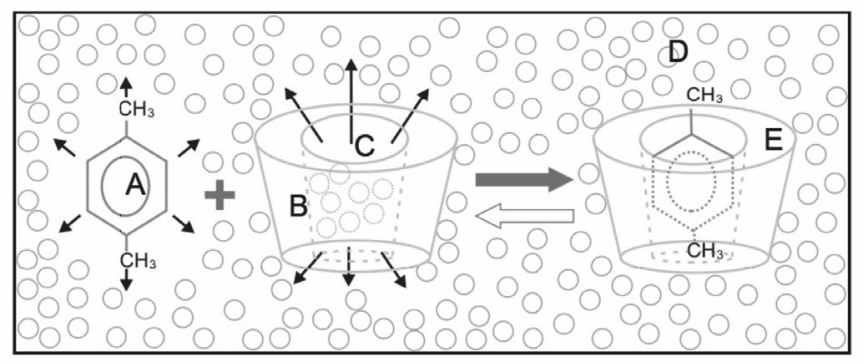

FIGURE 4 - Graphical representation of the formation of inclusion complexes. A: drug molecule; B: cyclodextrin (CD) molecule; C: CD cavity; D: water molecules; E: drug-CD complex. Adapted from: Szejtli, 1998; Veiga et al., 2006.

Furthermore, other forces are involved in the formation and stabilization of inclusion complexes, such as van der Waals interactions (dipole-dipole interaction and London dispersion forces), 3-center, 2-electron bonds (between guest molecule and CD hydroxyl groups), hydrophobic interactions, release of deformation energy from the macromolecular ring of CDs, and steric effects (Saenger, 1980; Bekers et al., 1991; Szejtli, 1998; Bibby et al., 2000; Flasinski et al., 2010).

The complexes formed are usually more water soluble than the active ingredients they contain as well as more stable in solution form. They also dissociate easily in order to release the drug molecule (Lofttson et al., 2005 a, b; Wintgens, Amiel, 2010).
Obtaining complexes with CDs may occur in the liquid, semi-solid or solid phases. In the liquid phase, the following methods have been suggested: coprecipitation, coevaporation, neutralization, freeze-drying, and drying by pulverization. In the solid phase, the most common methods are grinding or supercritical fluid technology, while malaxation is employed in the semi-solid phase (Valle, 2004).

Drug-CD complexes have an extremely rapid and dynamic formation and dissociation kinetics in solution form, continually forming and dissociating by covalent bonds. Complex dissociation is expressed quantitatively by the dissociation constant $(\mathrm{Kc})$, where [drug-CD], [drug] and $[\mathrm{CD}]$ are the concentrations of the complexed drug, the free drug and the free $\mathrm{CD}$, respectively. This dissociation constant ranges from 0 to $10^{5}$, where 0 indicates that the drug is incapable of forming a complex with $\mathrm{CD}$ and $10^{5}$ indicates the upper limit of drug-CD complexes (Tompson, 1997; Stella, Rajewski, 1997; Veiga et al., 2006; Loftsson et al., 2007; Rafati et al., 2009).

$$
\mathrm{Kc}=\frac{[\text { drug-CD }]}{[\text { drug }][\mathrm{CD}]}
$$

The dissociation kinetics will be inversely proportional to the strength of the bond between the CD and the drug, i.e., the slower the dissociation kinetics, the stronger the drug-CD bond $(\mathrm{Kc})$. Even in this situation, the dissociation velocity of the complexes is considered to be practically instantaneous (Loftsson et al., 2007).

There are several techniques for characterizing inclusion complexes, with X-ray diffraction, Fourier transform infrared (FTIR) spectroscopy, thermal analysis, Raman spectroscopy, solubility and scanning electron microscopy (SEM) being the most significant ones (Veiga et al., 2006; Heise et al., 2010; Tsai et al., 2010; Jug et al., 2011).

Molecular modeling studies have gained strong emphasis in the investigation of complexation with CDs. This allows the construction of three-dimensional models of drug-CD complexes, visualization of structural integrity, and intra- and intermolecular interactions (Seridi, Boufelfel, 2011; Leila et al., 2011; Eid et al., 2011; Ge et al., 2011; Mishur et al., 2011).

\section{CYCLODEXTRINS IN THE PHARMACEUTICAL INDUSTRY}

CDs and their derivatives are present in several areas, most notably in the pharmaceutical industry, where they are extensively used because of their complexing 
properties that are capable of modifying the physicochemical characteristics of poorly water-soluble drugs, thus changing the dissolution profile of their solid dosage forms (Loftsson, Duchêne, 2007).

The first pharmaceutical product using CDs in its formulation was E2/ $\beta-C D$ prostaglandin, in the form of a sublingual tablet, which was launched in Japan in
1976. The use of CDs for the purpose of modifying drug properties is a reality in the pharmaceutical industry, and currently, it is possible to name about 40 products formulated with CDs on the global market, especially in Europe, Japan, and USA. Table VI details several CD-containing pharmaceutical products (Loftsson et al., 2005 b; Loftsson, Duchêne, 2007).

TABLE VI - Pharmaceutical products containing cyclodextrins (CDs) (Loftsson et al., 2004; Szejtli 2004; Loftsson et al., 2005 a, b; Loftsson, Duchêne, 2007)

\begin{tabular}{|c|c|c|c|}
\hline DRUG / CD & TRADE NAME & DOSAGE FORM & COUNTRY \\
\hline \multicolumn{4}{|l|}{$\alpha-C D$} \\
\hline Alprostadil (PGE1) & Provastatin ${ }^{\circledR}$, Rigidur ${ }^{\circledR}$ & $\begin{array}{l}\text { Solution, intravenous } \\
\text { solution }\end{array}$ & Japan, Europe, USA \\
\hline OP -1206 & Opalmon ${ }^{\circledR}$ & Tablet & Japan \\
\hline Cefotiam hexetil hydrochloride & Pansporin $\mathrm{T} \circledR$ & Tablet & Japan \\
\hline \multicolumn{4}{|l|}{$\beta-C D$} \\
\hline Benexate hydrochloride & Ulgut $\AA$, Lonmiel $®$ & Capsule & Japan \\
\hline Cephalosporin (ME 1207) & Meiact ${ }^{\circledR}$ & Tablet & Japan \\
\hline Chlordiazepoxide & Transillium $\mathbb{R}$ & Tablet & Argentina \\
\hline Dexamethasone & Glymesason ${ }^{\circledR}$ & Cream & Japan \\
\hline Diphenhydramine hydrochloride, Chlorotheophylline & Stada-Travel ${ }^{\circledR}$ & Sublingual tablet & Europe \\
\hline Iodine & Mena-Gargle ${ }^{\circledR}$ & Solution & Japan \\
\hline Nicotine & Nicorette $\AA$, Nicogum $\AA$ & $\begin{array}{l}\text { Sublingual tablet, } \\
\text { chewing gum }\end{array}$ & Europe \\
\hline Nimesulide & Nimedex ${ }^{\circledR}$ & Tablet & Europe \\
\hline Nitroglycerin & Nitropen ${ }^{\circledR}$ & Sublingual tablet & Japan \\
\hline Omeprazole & Omebeta ${ }^{\circledR}$ & Tablet & Europe \\
\hline PGE2 & Prostarmon E® & Sublingual tablet & Japan \\
\hline Piroxicam & $\begin{array}{l}\text { Brexin }{ }^{\circledR} \text {, Flofene }{ }^{\circledR}, \\
\text { Cicladol } \AA\end{array}$ & $\begin{array}{l}\text { Tablet, suppository, } \\
\text { solution }\end{array}$ & Europe and Brazil \\
\hline Tiaprofenic acid & Surgamyl® & Tablet & Europe \\
\hline \multicolumn{4}{|l|}{ 2-hydroxypropyl- $\beta$-CD } \\
\hline Cisapride & Prepulsid ${ }^{\circledR}$ & Suppository & Europe \\
\hline Itraconazole & Sporanox ${ }^{\circledR}$ & $\begin{array}{c}\text { Oral solution and } \\
\text { intramuscular injection }\end{array}$ & Europe, USA \\
\hline Mitomycin & Mitozytrex ${ }^{\circledR}$ & Intravenous infusion & Europe, USA \\
\hline \multicolumn{4}{|l|}{ Methyl- $\beta$-CD } \\
\hline Chloramphenicol & Clorocil ${ }^{\circledR}$ & Ophthalmic solution & Europe \\
\hline $17 \beta$-estradiol & Aerodiol ${ }^{\circledR}$ & Nasal spray & Europe \\
\hline \multicolumn{4}{|l|}{ Sulfobutylether- $\beta-C D$} \\
\hline Voriconazole & Vfend $®$ & Intravenous solution & Europe, USA \\
\hline Ziprasidone mesylate & Geodon ${ }^{\circledR}$, Zeldox ${ }^{\circledR}$ & Intravenous solution & Europe, USA \\
\hline \multicolumn{4}{|l|}{ 2-hydroxypropyl- $\gamma$-CD } \\
\hline Diclofenac sodium & Voltaren $®$ & Ophthalmic solution & Europe \\
\hline Tc-99m teoboroxime & Cardiotec $\mathbb{R}$ & Intravenous solution & USA \\
\hline
\end{tabular}




\section{FORMATION OF TERNARY COMPLEXES}

When a water-soluble polymer, a CD and a drug are mixed together in a solution to obtain the so-called ternary complexes, it is possible to increase drug solubilization, when compared to the polymer and CD separately, which is a result of the synergistic effect between these components (Loftsson et al., 1994). An example is the synergistic effect resulting from the addition of hydroxypropyl methylcellulose (HPMC) to the complex formed by SBE- $\beta-C D$ and carbamazepine, with a consequent increase in drug solubility in the resulting ternary complex (Smith et al., 2005).

Formulations containing drug:CD complexes with the addition of a water-soluble polymer have proven to be capable of increasing the bioavailability of formulations while reducing the amount of CD by up to $80 \%$ (Loftsson, Fridriksdóttir, 1998; Mura et al., 2001). In the presence of water, the polymer aids in the wettability of particles, resulting in accelerated dissolution and increased amount of drug delivered in vitro (Lahiani-skiba et al., 2006).

The interaction of water-soluble polymers with drug molecules may occur by means of ion-ion, ion-dipole and dipole-dipole electrostatic bonds, van der Waals force, or 3-center, 2-electron bonds (Ribeiro et al., 2003). Similarly, the interaction between polymers and CDs and drug:CD complexes begins to occur on the external surface of the CD molecule. CDs, polymers and drug:CD complexes form aggregates capable of solubilizing drugs and other hydrophobic molecules (Loftsson et al., 2007), as shown in Figure 5.
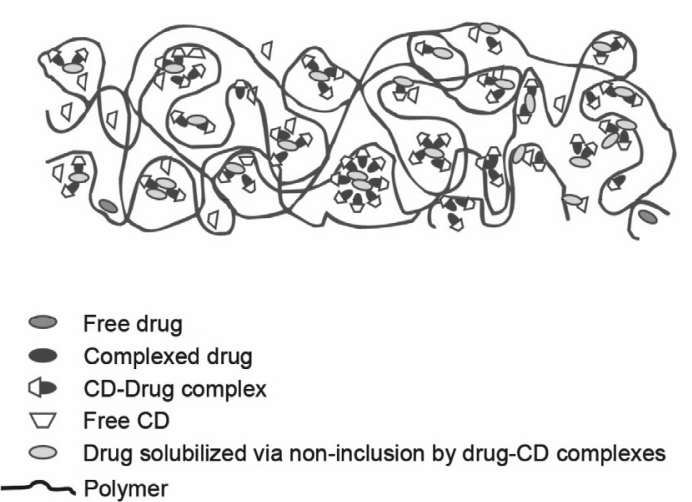

FIGURE 5 - Representation of ternary complex formation between drugs, cyclodextrins (CDs) and water-soluble polymers. Source: Veiga et al., 2006.

Several types of interactions between polymers and drugs may be established as a result of the structural difference and polarity of $\mathrm{CD}$ molecules, which may give rise to various complexation efficiencies. Povidone (PVP) and HPMC polymers were evaluated in the complexation of vinpocetine with $\beta-\mathrm{CD}$ and SBE- $\beta-\mathrm{CD}$. The best complexation efficiency results were obtained for PVP with $\beta-C D$ and for HPMC with SBE- $\beta$-CD (Ribeiro et al., 2003).

The resulting chemical structure of the drug is still unknown, as is the nature of the interaction between CDs and the water-soluble polymer, but it is recognized that, in aqueous solutions, polymers stabilize micelles and other types of aggregates, reduce CD mobility and increase the solubility of complexes by changing the hydration properties of CD molecules (Loftsson et al., 2005b).

This process can be accelerated by heating the ternary system. Thus, it is possible to activate the bonds between system components during the preparation of complexes by heating them in an autoclave $\left(120\right.$ to $\left.140^{\circ} \mathrm{C}\right)$ for 20 to 40 minutes, in an ultrasound bath (over $30^{\circ} \mathrm{C}$ ) for 1 hour, or even with microwaves at $40{ }^{\circ} \mathrm{C}$ for 5 minutes (Loftsson et al., 2005b).

Thermodynamic parameters (entropy and enthalpy) prove that different forces and/or mechanisms are at play in the formation of the complex, depending on the presence or absence of a polymer. Addition of polymers changes the entropy $\left(\Delta S^{\circ}\right)$ of the system, which becomes more negative, indicating the formation of a more organized structure with greater enthalpy (Loftsson et al., 1994).

Studies have proven that HPMC and PVP increase the complexation of hydrocortisone, dexamethasone and naproxen with $\beta$-CD (Ammar et al., 2006). Valero and colleagues (2003) observed that, at low PVP concentrations, the complexation process occurs entropically, and in larger proportions, it occurs enthalpically.

\section{COMPLEXATION EFFICIENCY AND THE STA- BILITY CONSTANT}

The stability constant $\left(\mathrm{K}_{\mathrm{C}}\right)$, calculated from the phase solubility diagram (drug concentration x CD concentration), can be considered an apparent stability constant for several complexes, describing the combined effect of various structures on the solubility of a drug. Accordingly, a definition for complexation efficiency (CE) as a more precise method for evaluating the solubilizing effect of CDs has been proposed (Loftsson et al., 2007).

The stability constant of a complex is determined from the slope of the phase diagram and the intrinsic solubility of a drug $\left(\mathrm{S}_{0}\right)$ (Equation 1). Theoretically, the intersection $\left(\mathrm{S}_{\text {int }}\right)$ of the phase solubility diagram should be identical to $\mathrm{S}_{0}$. However, drugs with an aqueous solubility of less than $0.1 \mathrm{mM}$ show an intersection in the phase solubility diagram that is generally much greater than $\mathrm{S}_{0}$, 
thus resulting in imprecise $\mathrm{K}_{\mathrm{C}}$ values. Therefore, $\mathrm{CE}$ is calculated from the slope of phase solubility diagrams and is independent of $\mathrm{S}_{0}$ and $\mathrm{S}_{\text {int }}$, in accordance with Equation 2 (Loftsson et al., 2007). In Equation 3, $\mathrm{K}_{1: 1}$ represents the stability constant 1:1 ratio between drug and $\mathrm{CD}$, and $\mathrm{D}$ represents drug concentration.

$$
\begin{gathered}
\mathrm{K}_{\mathrm{C}}=\frac{\text { Slope }}{\mathrm{S}_{0} \mathrm{X}(1-\text { slope })} \\
\mathrm{CE}=\mathrm{S}_{0} \cdot \mathrm{K}_{1: 1}=\frac{[\mathrm{D} / \mathrm{CD}]}{[\mathrm{CD}]}=\frac{\text { Slope }}{(1-\text { slope })}
\end{gathered}
$$

Some researchers consider that complexes with $\mathrm{K}_{\mathrm{C}}$ values ranging between 200 and $5000 \mathrm{M}^{-1}$ are applicable to dosage formulations, while $\mathrm{K}_{\mathrm{C}}$ values between 7 and $100 \mathrm{M}^{-1}$ were deemed sufficient by others, because they were able to improve the physical and chemical properties of drugs compared to non-complexed forms (Veiga et al., 2006).

$\mathrm{K}_{\mathrm{C}}$ values are widely used to determine the stoichiometry of complexes, as well as to compare the affinity of drugs for CDs, thus determining whether the addition of water-soluble polymers to the system actually results in greater interaction between the components (Loftsson et al., 2007).

\section{POLYMERS USED TO OBTAIN TERNARY COMPLEXES}

Obtaining complexes with CDs, drugs and watersoluble polymers has gained greater acceptance due to the relatively low cost of polymers (Lahiani-Skiba et al., 2006). The most important requirements in choosing polymers to form inclusion complexes with drugs and CDs are water solubility and absence of biological activity. The most commonly used polymers for this purpose may be classified as natural, semi-synthetic and synthetic (Veiga et al., 2006), as detailed in Table VII.

There is no pre-established range of ideal polymer concentration for obtaining ternary complexes. However, it is known that, at high concentrations, the viscosity of the medium increases, thus impairing complexation. The amount of polymer must be such that the solubilizing effect is maximized, but not sufficient to cause a significant increase in viscosity (Ribeiro et al., 2003).

In studies by Loftsson and colleagues (1994) with hydrocortisone, $17 \beta$-estradiol and triamcinolone in an HP$\beta-C D 10 \%(\mathrm{p} / \mathrm{v})$ aqueous solution, the ideal concentration of polymers ranged from 0.05 to $0.25 \%(\mathrm{p} / \mathrm{v})$ and greater
TABLE VII - Polymers most commonly used to obtain ternary complexes

\begin{tabular}{ll}
\hline $\begin{array}{l}\text { Nature of } \\
\text { polymers }\end{array}$ & Polymer \\
\hline Natural & Pectin \\
& Mucin \\
& Agar \\
& Alginic acid \\
& Carrageenin \\
& Casein \\
& Schizophyllan \\
& Gelatin \\
\hline Semi-synthetic & Methyl cellulose (MC) \\
& Hydroxyethyl cellulose (HEC) \\
& Hydroxypropyl cellulose (HPC) \\
& Hydroxyethyl methyl cellulose (HEMC) \\
& Carboxymethyl cellulose (CMC) \\
\hline Synthetic & Povidone (PVP) \\
& Polyethylene glycol (PEG) \\
& Copovidone \\
& Polyvinyl alcohol (PVA)
\end{tabular}

concentrations led to a reduction in drug solubility. Table VIII details the complexation solubility and efficiency of some drugs in their free form and in ternary complexes.

\section{PHARMACEUTICAL APPLICATIONS OF TER- NARY INCLUSION COMPLEXES}

Most drugs with low aqueous solubility have organic solvents, emulsifiers and extreme $\mathrm{pH}$ conditions in their formulations, which can cause irritation and other adverse reactions (Del Valle, 2004). The drug:CD:polymer complexes can be administered in any dosage form for the treatment of a variety of ailments, depending on the biological activity of the complexed drug. Research on ternary complexes has gained prominence in recent decades, and it is therefore possible to find a considerable number of studies in which drug:CD:water-soluble polymers obtained for several drugs are described (Table IX).

\section{CONCLUSION}

Improving the solubility of poorly soluble drugs is one of the main applications of CDs and their derivatives, which have the ability to encapsulate organic molecules in their cavities, thus forming inclusion complexes, which 
TABLE VIII - Solubility values for some drugs in their free form $\left(\mathrm{S}_{0}\right)$ and in ternary complexes $\left(\mathrm{S}_{\text {TERNARY }}\right)$, and their respective complexation efficiency (CE) values (Adapted from Brewster and Loftsson, 2007)

\begin{tabular}{lcccccc}
\hline Drug & $\begin{array}{c}\text { Cyclodextrin } \\
(\mathrm{CD})\end{array}$ & Polymer & $\begin{array}{c}\text { Polymer } \\
\text { concentration }\end{array}$ & $\begin{array}{c}\mathrm{S}_{0} \\
(\mathrm{mg} / \mathrm{mL})\end{array}$ & $\begin{array}{c}\mathrm{S}_{\text {TERNARY }} \\
(\mathrm{mg} / \mathrm{mL})\end{array}$ & CE \\
\hline Acetazolamide & HP- $\beta-C D$ & Absent & - & 0.64 & 3.60 & 0.197 \\
& HP- $\beta-C D$ & HPMC & $0.10 \%$ & 0.90 & 4.40 & 0.356 \\
& HP- $\beta-C D$ & CMC & $0.25 \%$ & 0.59 & 3.60 & 0.209 \\
& HP- $\beta-C D$ & PVP & $0.25 \%$ & 0.94 & 3.70 & 0.273 \\
\hline Carbamazepine & HP- $\beta-C D$ & Absent & - & 0.26 & 0.65 & 0.548 \\
& HP- $\beta-C D$ & HPMC & $0.10 \%$ & 0.33 & 8.00 & 0.829 \\
& HP- $\beta-C D$ & CMC & $0.25 \%$ & 0.18 & 8.40 & 0.709 \\
& HP- $\beta-C D$ & PVP & $0.25 \%$ & 0.28 & 8.50 & 0.701 \\
\hline Finasteride & RM- $\beta-C D$ & Absent & - & 0.06 & 12.30 & 0.708 \\
& RM- $\beta-C D$ & HPMC & $0.10 \%$ & 0.06 & 11.60 & 0.789 \\
& RM- $\beta-C D$ & CMC & $0.25 \%$ & 0.06 & 11.50 & 0.805 \\
& RM- $\beta-C D$ & PVP & $0.25 \%$ & 0.06 & 11.60 & 0.844 \\
\hline Oxazepam & HP- $\beta-C D$ & Absent & - & 0.05 & 2.10 & 0.109 \\
& HP- $\beta-C D$ & HPMC & $0.10 \%$ & 0.27 & 2.10 & 0.076 \\
& HP- $\beta-C D$ & CMC & $0.25 \%$ & 0.05 & 1.50 & 0.127 \\
& HP- $\beta-C D$ & PVP & $0.25 \%$ & 0.10 & 1.40 & 0.115 \\
\hline
\end{tabular}

$\mathrm{CMC}=$ carboxymethyl cellulose; $\mathrm{HP}-\beta-\mathrm{CD}=$ hydroxypropyl $-\beta-\mathrm{CD} ; \mathrm{HPMC}=$ hydroxypropyl methylcellulose $; \mathrm{PVP}=$ povidone; $\mathrm{RM}-\beta-\mathrm{CD}=$ randomly methylated- $\beta-\mathrm{CD}$.

TABLE IX - Ternary complexes between drugs, cyclodextrins (CDs) and water-soluble polymers, as described in the scientific literature

\begin{tabular}{|c|c|c|c|}
\hline Drug & $\mathrm{CD}$ & Water-soluble polymer & Reference \\
\hline \multirow[t]{2}{*}{$\overline{17 \beta \text {-estradiol }}$} & $\mathrm{HP}-\beta-\mathrm{CD}$ & $\mathrm{CMC}$ & Loftsson et al., 1994 \\
\hline & $\mathrm{HP}-\beta-\mathrm{CD}$ & PVP & Loftsson, Brewster, 1996 \\
\hline \multirow{3}{*}{ Acetazolamide } & $\beta-C D$ & HPMC, CMC, PVP & Loftsson, Fridrilksdóttir, 1998 \\
\hline & $\mathrm{HP}-\beta-\mathrm{CD}$ & CMC, PVP & Loftsson et al., 1994 \\
\hline & $\mathrm{HP}-\beta-\mathrm{CD}$ & HPMC, CMC, PVP & Loftsson et al., 2005b \\
\hline $\begin{array}{l}\text { Triamcinolone } \\
\text { acetonide }\end{array}$ & $\mathrm{HP}-\beta-\mathrm{CD}$ & $\mathrm{CMC}$ & Loftsson et al., 1994 \\
\hline \multirow[t]{2}{*}{ Alprazolam } & $\beta-\mathrm{CD}$ & HPMC, CMC, PVP & Loftsson, Fridrilksdóttir, 1998 \\
\hline & $\mathrm{HP}-\beta-\mathrm{CD}$ & $\mathrm{CMC}$ & Loftsson et al., 1994 \\
\hline \multirow[t]{4}{*}{ Carbamazepine } & SBE- $\beta-C D$ & HPMC, PVP & Smith et al., 2005 \\
\hline & $\mathrm{HP}-\beta-\mathrm{CD}$ & CMC, PVP & Loftsson et al., 1994 \\
\hline & $\beta-C D$ & HPMC, CMC, PVP & Loftsson, Fridrilksdóttir, 1998 \\
\hline & $\mathrm{HP}-\beta-\mathrm{CD}$ & HPMC, CMC, PVP & Brewster, Loftsson, 2007 \\
\hline Celecoxib & $\mathrm{HP}-\beta-\mathrm{CD}$ & HPMC, PEG, PVP & Chowdary, Srinivas, 2006 \\
\hline Clotrimazol & $\mathrm{HP}-\beta-\mathrm{CD}$ & CMC, PVP & Loftsson et al., 1994 \\
\hline \multirow[t]{2}{*}{ Dexamethasone } & $\mathrm{HP}-\beta-\mathrm{CD}$ & HPMC & Loftsson et al., 1994 \\
\hline & $\beta-\mathrm{CD}$ & HPMC, CMC, PVP & Loftsson, Fridrilksdóttir, 1998 \\
\hline Diazepam & $\mathrm{HP}-\beta-\mathrm{CD}$ & $\mathrm{CMC}$ & Loftsson et al., 1994 \\
\hline Econazole & $\mathrm{HP}-\beta-\mathrm{CD}$ & CMC, PVP & Loftsson et al., 1994 \\
\hline \multirow[t]{2}{*}{ Ethoxzolamide } & $\mathrm{HP}-\beta-\mathrm{CD}$ & CMC, PVP & Loftsson et al., 1994 \\
\hline & $\beta-C D$ & HPMC, CMC, PVP & Loftsson, Fridrilksdóttir, 1998 \\
\hline
\end{tabular}


TABLE IX - Ternary complexes between drugs, cyclodextrins (CDs) and water-soluble polymers, as described in the scientific literature (cont.)

\begin{tabular}{|c|c|c|c|}
\hline Drug & $\mathrm{CD}$ & Water-soluble polymer & Reference \\
\hline \multirow[t]{2}{*}{ Finasteride } & $\mathrm{RM}-\beta-\mathrm{CD}$ & HPMC, CMC, PVP & Brewster, Loftsson, 2007 \\
\hline & $\mathrm{HP}-\beta-\mathrm{CD}$ & PVP & Asbahr et al., 2009 \\
\hline Gemfibrozil & $\beta-\mathrm{CD}$ & PVP & Sami, Philip, Pathak, 2010 \\
\hline Gefitinib & $\mathrm{HP}-\beta-\mathrm{CD}$ & PVP, HPMC & Phillip Lee et al., 2009 \\
\hline Glibenclamide & $\beta-\mathrm{CD}, \mathrm{HP}-\beta-\mathrm{CD}, \mathrm{SBE}-\beta-\mathrm{CD}$ & HPMC & Savolainen et al., 1998 \\
\hline Glimepiride & $\beta-\mathrm{CD}, \mathrm{HP}-\beta-\mathrm{CD}, \mathrm{SBE}-\beta-\mathrm{CD}$ & HPMC, PEG, PVP & Ammar et al., 2006 \\
\hline \multirow[t]{2}{*}{ Griseofulvin } & $\alpha-C D, \beta-C D$ and $\gamma-C D$ & PEG & Wulff, Aldén, 1999 \\
\hline & $\beta-C D$ & $\mathrm{CMC}$ & Dhanaraju et al., 1998 \\
\hline \multirow[t]{4}{*}{ Hydrocortisone } & $\mathrm{HP}-\beta-\mathrm{CD}$ & $\mathrm{CMC}$ & Loftsson et al., 1994 \\
\hline & $\mathrm{HP}-\beta-\mathrm{CD}$ & HPMC, PVP & Loftsson, Sigurdardottir, 1994 \\
\hline & $\mathrm{HP}-\beta-\mathrm{CD}$ & HPMC, CMC, PVP & Loftsson et al., 2005b \\
\hline & $\mathrm{RM}-\beta-\mathrm{CD}$ & HPMC, CMC, PVP & Loftsson et al., 2005b \\
\hline Indomethacin & $\alpha-C D, \beta-C D$ and $\gamma-C D$ & PEG & Wulff, Aldén, 1999 \\
\hline Irbesartan & $\beta-C D$ & PEG, PVP & Hirlekar, Sonawane, Kadam, 2009 \\
\hline Lamivudine & $\beta-C D$ & PVA & Selvam, Geetha, 2008 \\
\hline Lamotrigine & $\beta-C D$ & PEG, PVP & Shinde et al., 2008 \\
\hline Lovastatin & $\beta-C D, R M-\beta-C D$ & PVP & Süle, Csempesz, 2008 \\
\hline Meloxicam & $\mathrm{HP}-\beta-\mathrm{CD}$ & PVP & El-Maradny et al., 2008 \\
\hline \multirow[t]{2}{*}{ Methazolamide } & $\beta-C D$ & HPMC, CMC, PVP & Loftsson, Fridrilksdóttir, 1998 \\
\hline & $\mathrm{HP}-\beta-\mathrm{CD}$ & HPMC, CMC, PVP & Loftsson et al., 2005b \\
\hline Miconazol & $\mathrm{HP}-\beta-\mathrm{CD}$ & $\mathrm{CMC}$ & Loftsson et al., 1994 \\
\hline Midazolam & SBE- $\beta-C D$ & HPMC & Loftsson et al., 2001 \\
\hline Naproxen & $\beta-\mathrm{CD}, \mathrm{HP}-\beta-\mathrm{CD}$ & PVP & Mura et al., 2001 \\
\hline Nicardipine & $\beta-\mathrm{CD}$ & PEG & Quaglia et al., 2001 \\
\hline \multirow[t]{2}{*}{ Oxazepam } & $\mathrm{HP}-\beta-\mathrm{CD}$ & CMC, PVP & Loftsson et al., 1994 \\
\hline & $\mathrm{HP}-\beta-\mathrm{CD}$ & HPMC, CMC, PVP & Brewster, Loftsson, 2007 \\
\hline \multirow[t]{2}{*}{ Prednisolone } & $\mathrm{HP}-\beta-\mathrm{CD}$ & $\mathrm{CMC}$ & Loftsson et al., 1994 \\
\hline & $\beta-C D$ & HPC & Uekama et al., 1983 \\
\hline \multirow[t]{3}{*}{ Progesterone } & $\mathrm{HP}-\beta-\mathrm{CD}$ & PEG & Nandi et al., 2003 \\
\hline & $\beta-C D$ & PEG & Lahiani-Skiba et al., 2006 \\
\hline & $\mathrm{HP}-\beta-\mathrm{CD}$ & CMC, PVP & Loftsson et al., 1994 \\
\hline Simvastatin & $\beta-C D, R M-\beta-C D$ & PVP & Süle, Csempesz, 2008 \\
\hline \multirow[t]{3}{*}{ Sulfamethoxazole } & HP- $\beta-C D$ & CMC, PVP & Loftsson et al., 1994 \\
\hline & $\beta-C D$ & HPMC, CMC, PVP & Loftsson, Fridrilksdóttir, 1998 \\
\hline & $\mathrm{HP}-\beta-\mathrm{CD}$ & HPMC, CMC, PVP & Loftsson et al., 2005b \\
\hline Temazepam & $\mathrm{HP}-\beta-\mathrm{CD}$ & $\mathrm{CMC}$ & Loftsson et al., 1994 \\
\hline Terfenadine & $\beta-C D$ & $\mathrm{CMC}$ & Choi et al., 2001 \\
\hline Triclosan & $\beta-\mathrm{CD}$ & $\mathrm{CMC}$ & Loftsson, 1999 \\
\hline Trimethoprim & $\mathrm{HP}-\beta-\mathrm{CD}$ & PVP & Loftsson et al., 1994 \\
\hline Tropicamide & $\mathrm{HP}-\beta-\mathrm{CD}$ & HPMC, CMC, PVP & Cappello et al., 2001 \\
\hline Vinpocetine & $\beta-C D$, SBE- $\beta-C D$ & HPMC, PVP & Ribeiro et al., 2003 \\
\hline
\end{tabular}

$\mathrm{CMC}=$ carboxymethyl cellulose; HP- $\beta-\mathrm{CD}=$ hydroxypropyl $-\beta-\mathrm{CD} ; \mathrm{HPMC}=$ hydroxypropyl methylcellulose; $\mathrm{PEG}=$ polyethylene glycol; $\mathrm{PVP}=$ povidone; RM- $\beta-\mathrm{CD}=$ randomly methylated- $\beta-\mathrm{CD} ; \mathrm{SBE}-\beta-\mathrm{CD}=$ sulfobutylether- $\beta-\mathrm{CD}$. 
in turn modify the physicochemical characteristics of such drugs. The drug:CD:water-soluble polymer complex represents an attractive alternative, especially in cases where a high amount of $C D$ is required for complexation, which significantly increases the volume of dosage forms. Thus, it is possible to obtain solid-form medications with an optimized dissolution profile, which may result in improved bioavailability.

\section{REFERENCES}

AMMAR, H.O.; SALAMA, H.A.; GHORAB, M.; MAHMOUD, A.A. Implication of inclusion complexation of glimepiride in cyclodextrin-polymer systems on its dissolution, stability and therapeutic efficacy. Int. J. Pharm., v.320, p.53-57, 2006.

ASBAHR, A.C.; FRANCO, L.; BARISON, A.; SILVA, C.W.; FERRAZ, H.G.; RODRIGUES, L.N. Binary and ternary inclusion complexes of finasteride in HPbetaCD and polymers: preparation and characterization. Bioorg. Med. Chem., v.17, p.2718-2723, 2009.

BEKERS, O.; UIJTENDAAL, E.V.; BEIJNEN, J.H.; UNDERBERG, W.J.M. Cyclodextrins in the pharmaceutical field. Drug Dev. Ind. Pharm., v.17, p.1503-1549, 1991.

BIBBY, D.C.; DAVIES, N.M.; TUCKER, I.G. Mechanism by which cyclodextrins modify drug release from polymeric drug delivery systems. Int. J. Pharm., v.197, p.1-11, 2000.

BREWSTER, M.; LOFTSSON, T. Cyclodextrins as pharmaceutical solubilizers. Adv. Drug Deliver. Rev., v.59, p.645-666, 2007.

CAPPELLO, B.; CARMIGNANI, C.; LERVOLINO, M.; FABRIZIO SAETTONE, M. Solubilization of tropicamide by hydroxypropyl- $\beta$-cyclodextrin and water-soluble polymers: in vitro/in vivo studies. Int. J. Pharm., v.213, p.75-81, 2001.

CARRIER, R.L.; MILLER, L.A.; AHMED, I. The utility of cyclodextrins for enhancing oral bioavailability. J. Control Release, v.123, p.78-99, 2007.

CHOI, H.G.; LEE, B.J; HAN, J.H.; LEE, M.K.; PARK, K.M.; YONG, C.S.; RHEE, J.D.; KIM, Y.B; KIM, C.K. Terfenadine- $\beta$-cyclodextrin inclusion complex with antihistaminic activity enhancement. Drug Dev. Ind. Pharm., v.27, p.857-862, 2001.
CHOWDARY, K.P.R.; SRINIVAS, S.V. Influence of hydrophilic polymers on celecoxib complexation with hydroxypropyl $\beta$-cyclodextrin. AAPS Pharm. Sci. Tech., v.7, p.3, 2006.

DEL VALLE, E.M.M. Cyclodextrin and their uses: a review. Process Biochem., v.39, p.1033-1046, 2004.

DHANARAJU, M.D.; KUMARAN, K.S.; BASKARAN, T.; SREE RAMA MOORTHY, M. Enhancement of bioavailability of griseofulvin by its complexation with $\beta$-cyclodextrin. Drug Dev. Ind. Pharm., v.24, p.583-587, 1998.

DUCHÊNE, D.; WOUESSIDJEWE, D. Physicochemical characteristics and pharmaceutical uses of cyclodextrin derivatives - Part I. Pharm. Tech., v.6, p.21-29, 1990a.

DUCHÊNE, D.; WOUESSIDJEWE, D. Physicochemical characteristics and pharmaceutical uses of cyclodextrin derivatives - Part II. Pharm. Tech., v.14, p.22-30, 1990b.

EID, E.; ABDUL, A.; SULIMAN, F.E.A; SUKARI, M.A.; RASEDEE, A.; FATAH, S.S. Characterization of the inclusion complex of zerumbone with hydroxypropyl- $\beta$ cyclodextrin. Carbohydr. Polym., v.83, p.1707-1714, 2011.

EL-MARADNY, H.A; MORTADA, S.A.; KAMEL, O.A.; HIKAL, A.H. Characterization of ternary complexes of meloxicam-HPbetaCD and PVP or L-arginine prepared by the spray-drying technique. Acta Pharm., v.58, p.455-466, 2008.

FLASINSKI, M.; BRONIATOWSKI, M.; MAJEWSKI, J.; DYNAROWICZ-LATKA, P. X-ray grazing incidence diffraction and Langmuir monolayer studies of the interaction of $\beta$-cyclodextrin with model lipid membranes. J. Colloid. Interf. Sci., v.348, p.511-521, 2010.

GARNERO, C.; ZOPPI, A.; GENOVESE, D.; LONGI, M. Studies on trimethoprim:hydroxypropyl- $\beta$-cyclodextrin: aggregate and complex formulation. Carboyd. Res., v.345, p.2550-2556, 2010.

GE, X.; HE, J.; YANG, Y.; FENGMING, Q.I.; HUANG, Z.; RUIHUA, LU; HUANG, L; YAO, X. Study on inclusion complexation between plant growth regulator 6-benzylaminopurine and $\beta$-cyclodextrin: Preparation, characterization and molecular modeling. J. Mol. Struct., v.994, p.163-169, 2011. 
GRANT, N.; ZHANG, H. Poorly water-soluble drug nanoparticles via an emulsion-freeze-drying approach. $J$. Colloid Interf. Sci., v.356, p.573-578, 2011.

HEISE, H.M.; KUCKUK, R.; BERECK, A.; RIEGEL, D. Infrared spectroscopy and Raman spectroscopy of cyclodextrin derivatives and their ferrocene inclusion complexes. Vib. Spectrosc., v.53, p.19-23, 2010.

HIRLEKAR, S.R; SONAWANE, S.N.; KADAM, V.J. Studies on the effect of water-soluble polymers on drugcyclodextrin complex solubility. AAPS PharmSciTec., v.10, p.858-863, 2009.

IMAI, T.; IRIE, T.; OTAGIRI, M.; UEKAMA, K.; YAMASAKI, M. Comparative study on inclusion complexation of antiinflammatory drugs flurbiprofen with $\beta$-cyclodextrin and methylated- $\beta$-cyclodextrin. J. Inclus. Phenom. Macro., v.2, p.597-604, 1984.

JUG, M.; KOSALEC, I.; MAESTRELLI, F.; MURA, P. Analysis of triclosan inclusion complexes with $\beta$-cyclodextrin and its water-soluble polymeric derivative. J. Pharm. Biomed. Anal., v.54, p.1030-1039, 2011.

LAHIANI-SKIBA, M.; BARBOT, C.; BOUNOURE, F.; JOUDIEH, S.; SKIBA, M. Solubility and dissolution rate of progesterone-cyclodextrin-polymer systems. Drug Dev. Ind. Pharm., v.32, p.1043-1058, 2006.

LEILA, N.; SAKINA, H.; BOUHADIBA, A.; FATIHA, M.; LEILA, L. Molecular modeling investigation of paranitrobenzoic acid interaction in $\beta$-cyclodextrin. J. Mol. Liq., v.160, p.1-7, 2011.

LI, H.; XU, X.; LIU, M.; SUN, D.; LI, L. Microcalorimetric and spectrographic studies on host-guest interactions of $\alpha-, \beta$-, $\gamma$ - and $\mathrm{M} \beta$-cyclodextrin with resveratrol. Thermochim. Acta, v.510, n.1-2, p.168-172, 2010.

LIPINSKI, C.A. Drug-like properties and the cause of poor solubility and poor permeability. J. Pharmacol. Toxicol., v.44, n.4, p.235-249, 2000.

LOFTSSON, T.; BREWSTER, M. Cyclodextrins as pharmaceutical excipients. Pharm. Tech., v.5, p.26-34, 1997.

LOFTSSON, T.; JARBO, P.; MASSON, T; JAVINEN, T. Cyclodextrins in drug delivery. Expert Opin. Drug Deliver., v.2, p.335-351, 2005a.
LOFTSSON, T.; DUCHÊNE, D. Cyclodextrins and their pharmaceutical applications. Int. J. Pharm., v.329, p.1-11, 2007.

LOFTSSON, T.; MÁSSON, M.; BREWSTER, M.E. Selfassociation of cyclodextrins and cyclodextrin complexes. J. Pharm. Sci., v.93, p.1091-1099, 2004.

LOFTTSON, T.; HREINSDÓTTIR, D.; MÁSSON, M. Evaluation of cyclodextrin solubilization of drugs. Int. J. Pharm., v.302, p.18-28, 2005b.

LOFTTSON, T.; HREINSDÓTTIR, D.; MÁSSON, M. The complexation efficiency. J. Inclus. Phenom. Macro., v.57, p.545-552, 2007.

LOFTSSON, T.; SIGURDARDÓTTIR, A.M. The effect of hydroxypropyl methylcellulose on hydroxypropyl- $\beta$ cyclodextrin complexation of hydrocortisone and its permeability through hair mouse skin. Eur. J. Pharm. Sci., v.2, p.297-301, 1994.

LOFTSSON, T.; FRIDRIKSDÓTTIR, H.; SIGURDARDÓTTIR, A.M.; UEDA, H. The effect of water-soluble polymers on drug-cyclodextrin complexation. Int. J. Pharm., v.110, p.169-177, 1994.

LOFTSSON, T.; BREWSTER, M. E. Pharmaceutical applications of cyclodextrins. 1. Drug solubilization and stabilization. J. Pharm. Sci., v.85, p.1017-1025, 1996.

L O F T S S O N, T.; F R I D R I K S D Ó T T I R, H . ; GUDMUNDSDÓTTIR, T.K. The effect of water-soluble polymers on aqueous solubility of drugs. Int. J. Pharm., v.27, p.293-296, 1996.

LOFTSSON, T; FRIDRIKSDÓTTIR, H. The effect of watersoluble polymers on the aqueous solubility and complexing abilities of $\beta$-cyclodextrin. Int. J. Pharm., v.163, p.115-121, 1998.

LOFTSSON, T. Effect of cyclodextrins and polymers on triclosan availability and substantivity in toothpastes in vivo. J. Pharm. Sci., v.88, p.1254-1258, 1999.

L O F T S S ON, T.; G U D M UN D S D Ó T T I R, H .; SIGURJÓNSDÓTTIR, J.F.; SIGURDSSON, H.H.; SIGFÚSSON, S.D.; MÁSSON, M.; STEFÁNSSON, E. Cyclodextrin solubilization of benzodiazepines: formulation of midazolam nasal spray. Int. J. Pharm., v.212, p.29-40, 2001. 
MA, D.Q.; RAJEWSKI, R.A.; VELDE, D.V.; STELLA, V.J. Comparative effects of (SBE) $7 \mathrm{~m}-\beta-\mathrm{CD}$ and HP- $\beta-\mathrm{CD}$ on the stability of two anti-neoplastic agents, melphalan and carmustine. J. Pharm. Sci., v.89, p.275-287, 2000.

MISHUR, R.J.; GRIFFIN, M.E.; BATTLE, C.H.; SHAN, B.; JAYAWICKRAMARAJAH, J. Molecular recognition and enhancement of aqueous solubility and bioactivity of CD437 by $\beta$-cyclodextrin. Bioorg. Med. Chem. Lett., v.21, p.857-860, 2011.

MOSHER, G.; THOMPSON, D. Complexation and cyclodextrins. In: SWARBRICK, J.B. (Ed.). Encyclopedia of Pharmaceutical Technology. New York: Taylor \& Francis LTD, 2002. v.19, p.49-88.

MURA, P.; FAUCCI, M.T.; BETTINETTI, G.P. The influence of polyvivylpyrrolidone on naproxen complexation with hydroxypropyl- $\beta$-cyclodextrin. Eur. J. Pharm. Sci., v.13, p.187-194, 2001.

NANDI, I.; BATESON, M.; BARI, M.; JOSHI, H.N. Synergestic effect of PEG-400 and cyclodextrin in enhance solubility of progesterone. AAPS PharmSciTech., v.4, p.1-5, 2003.

PHILLIP LEE, Y.H.; SATHIGARI, S.; JEAN LIN, Y.J.; RAVIS, W.R.; CHADHA, G.; PARSONS, D.L.; RANGARI, V.K.; WRIGHT, N.; BABU, R.J. Gefitinib-cyclodextrin inclusion complexes: physico-chemical characterization and dissolution studies. Drug Dev. Ind. Pharm., v.35, p.1113-1120, 2009.

QUAGLIA, F.; VARRICHIO, G.; MIRO, A.; IMMACOLATA, L.A.; ROTONDA, M.; LAROBINA, D.; MENSITIERI, G. Modulation of drug release from hydrogels by using cyclodextrins: The case of nicardipine/ $\beta$-cyclodextrin system in crosslinked polyethylenglycol. J. Control Release, v.71, p.329-337, 2001.

RAFATI, A.A.; HAMNABARD, N.; GHASEMIAN, E.; NOJINI, Z.B. Study of inclusion complex formation between chlorpromazine hydrochloride, as an antiemetic drug, and $\beta$-cyclodextrin, using conductometric technique. Mater. Sci. Eng., v.29, p.791-795, 2009.

RIBEIRO, L.S.S.; FERREIRA, D.C.; VEIGA, F.J.B. Physicochemical investigation of the effects of watersoluble polymers on vipocetine complexation with $\beta$-cyclodextrin and its sulfobutyl ether derivative in solution and solid state. Eur. J. Pharm. Sci., v.20, p.253-266, 2003.
SAENGER, W. Cyclodextrin inclusion compounds in research and industry. Angew. Chem. Int. Edit., v.19, p.344-362, 1980 .

SAMI, F.; PHILLIP, B.; PATHAK, K. Effect of auxiliary substances on complexation efficiency and intrinsic dissolution rate of gemfibrozil-beta-CD complexes. AAPS PharmSciTech, v.11, p.27-35, 2010.

SAVOLAINEN, J.; JÄRVINEN, K.; TAIPALE, H.; JARHO, P.; LOFTSSON, T.; JÄRVINEN, T. Co-administration of a water-soluble polymer increases the usefulness of cyclodextrins in solid oral dosage forms. Pharm. Res., v.15, p.1696-1701, 1998.

SELVAM, A.P.; GEETHA, D. Ultrasonic studies on lamivudine: beta-cyclodextrin and polymer inclusion complexes. Pak. J. Biol. Sci., v.11, p.656-659, 2008.

SERIDI, L.; BOUFELFEL, A. Molecular modeling study of Lamotrigine/ $\beta$-cyclodextrin inclusion complex. J. Mol. Liq., v.58, p.151-158, 2011.

SHINDE, V.R.; SHELAKE, M.R.; SHETTY, S.S.; CHAVANPATIL, A.B.; PORE, Y.V.; LATE, S.G. Enhanced solubility and dissolution rate of lamotrigine by inclusion complexation and solid dispersion technique. J. Pharm. Pharmacol., v.60, p.1121-1129, 2008.

SMITH, J.S.; MACRAE, R.J.; SNOWDEN, M.J. Effect of SBE7- $\beta$-cyclodextrin complexation on carbamazepine release from sustained release beads. Eur. J. Pharm. Sci., v.60, p.73-80, 2005.

STELLA, V.J.; RAJEWSKI R. Cyclodextrins: Their future in drug formulation and delivery. Pharm. Res., v.14, p.556$567,1997$.

STELLA, V.J.; RAO, V.M.; ZANNOU, E.A. The pharmaceutical use of captisol: some surprising observations. J. Inclus. Phenom. Macro., v.44, p.29-33, 2002.

SÜLE, A.; CSEMPESZ, F. Colloid-physical characterization of supramolecular drug delivery systems. Acta Pharm Hung., v.78, p.59-67, 2008.

SZEJTLI, J. Introduction and general overview of cyclodextrin chemistry. Chem. Rev., v.98, p.1743-1753, 1998.

SZEJTLI, J. Medicinal application of cyclodextrins. Med. Care Res. Rev., v.14, p.353-386, 1994. 
SZEJTLI, J. Past, present and future of cyclodextrin research. Pure Appl. Chem. Rev., v.76, p.1825-1845, 2004.

THOMPSON, D.O. Cyclodextrins - enabling excipients: their present and future use in pharmaceuticals. Crit. Rev. Ther. Drug, v.14, p.1-104, 1997.

TSAI, Y.; TSAI, H.; WU, C.; TSAI, F. Preparation, characterisation and activity of the inclusion complex of paeonol with $\beta$-cyclodextrin. Food Chem., v.120, p.837$841,2010$.

UEKAMA, K.; IRIE, T. New perspectives in cyclodextrin pharmaceutical applications cyclodextrins derivatives as new drugs carriers. Int. J. Pharm., v.271, p.155-165, 2004.

UEKAMA, K.; OTAGARI, M. Cyclodextrins in drugs carrier systems. Chem. Rev., v.98, p.2045-2076, 1998.

UEKAMA, K.; OTAGIRI, M.; UEMURA, Y.; FUJINAGA, T.; ARIMORI, K.; MATSUO, N.; TASAKI, K.; SUGII, A. Improvement in oral bioavailability of prednisolone by $\beta$-cyclodextrin complexation in humans. J. Pharmdynamics., v.6, p.124-127, 1983.

UEKAMA, K.; HIRAYAMA, F.; ARIMA, H. Recent aspects of cyclodextrin-based drug delivery systems. J. Inclus. Phenom. Macro., v.56, p.3-8, 2006.
VALERO, M.; CARRILLO, C.; RODRÍGUEZ, L.J. Ternary naproxen: $\beta$-cyclodextrin:polyethylene glycol complex formation. Int. J. Pharm., v.265, p.141-149, 2003.

VALLE, E.M.M.D. Cyclodextrins and their uses: a review. Process Biochem., v.39, p.1033-1046, 2004.

VEIGA, F.; PECORELLI, C.; RIBEIRO, L. As ciclodextrinas em tecnologia farmacêutica. Coimbra: MinervaCoimbra, 2006. p.9-33.

WINTGENS, V.; AMIEL, C. Water-soluble $\gamma$-cyclodextrin polymers with molecular weight and their complex forming properties. Eur. Polym. J., v.46, p.1915-1922, 2010.

WULFF, M.; ALDÉM, M. Solid state of drug-cyclodextrin inclusion complexes in PEG 6000 prepared by a new method. Eur. J. Pharm. Sci., v.8, p.169-281, 1999.

ZIA, V.; RAJEWSKI, R.A.; STELLA, V.J. Effect of cyclodextrin charge on complexation of neutral and charged substrates: Comparison of sulfobutylether- $\beta$-cyclodextrin to hydroxypropyl- $\beta$-cyclodextrin. Pharm. Res., v.15, p.667673, 2001.

Received for publication on $20^{\text {th }}$ September 2010 Accepted for publication on $13^{\text {rd }}$ July 2011 
